\title{
Video-assisted thoracoscopic mediastinal lymph node dissection
}

\author{
Onkar V. Khullar, MD, and Sidhu P. Gangadharan, MD
}

Survival and appropriate surgical management of patients with non-small cell lung cancer (NSCLC) are predicated on accurate staging. The presence or absence of mediastinal lymph node ( $\mathrm{LN}$ ) metastases is a critical component to accurate staging, and therefore a key component of surgical management for NSCLC. ${ }^{1}$ Although the role for mediastinal LN sampling versus mediastinal $\mathrm{LN}$ dissection with regard to improvement in survival is still controversial, the necessity for LN assessment for staging purposes is undeniable. ${ }^{1-5}$

In addition, for early-stage NSCLC, both overall and disease-free survivals have been associated with the number of nodes sampled. ${ }^{6}$ As a result, current guidelines from the National Comprehensive Cancer Network recommend that all patients with resectable NSCLC should have an N1 and N2 node dissection, with at least 3 N2 stations sampled. ${ }^{3}$ Similar guidelines published by the European Society of Thoracic Surgeons recommend a complete systematic nodal dissection. ${ }^{4}$ Finally, the most recent guidelines from the American College of Chest Physicians state that there is sufficient evidence in the literature to support a grade $1 \mathrm{~B}$ recommendation that intraoperative systematic mediastinal LN sampling or dissection be performed. ${ }^{5}$ Unfortunately, few patients ultimately undergo sufficient LN dissection, with as many as $40 \%$ to $50 \%$ of patients having no mediastinal LNs removed at the time of lung resection. ${ }^{7}$

Lobectomy by video-assisted thoracoscopic surgery (VATS) is steadily becoming more commonplace and has been shown to be associated with equivalent or superior postoperative outcomes, as well as equivalent oncologic outcomes. ${ }^{8-10}$ Lobectomy by VATS with mediastinal LN dissection was first described in $1995 .{ }^{11}$ Since that time, a number of studies have been published comparing mediastinal LN dissection via thoracotomy with VATS. ${ }^{12-18}$ We review the technique and efficacy of VATS mediastinal LN dissection.

\section{TECHNIQUE}

The technique for lymphadenectomy by VATS remains similar to that for open thoracotomy. In the majority of

\footnotetext{
From the Division of Thoracic Surgery and Interventional Pulmonology, Beth Israel Deaconess Medical Center, Harvard Medical School, Boston, Mass.

Disclosures: Authors have nothing to disclose with regard to commercial support.

Presented at the 3rd International Minimally Invasive Thoracic Surgery Summit, Boston, Massachusetts, October 7-8, 2011

Received for publication Nov 17, 2011; revisions received May 10, 2012; accepted for publication May 15, 2012; available ahead of print June 7, 2012.

Address for reprints: Sidhu P. Gangadharan, MD, Division of Thoracic Surgery and Interventional Pulmonology, Beth Israel Deaconess Medical Center, 185 Pilgrim Rd, W/DC 201, Boston, MA 02215 (E-mail: sgangadh@bidmc.harvard.edu).

J Thorac Cardiovasc Surg 2012;144:S32-4

$0022-5223 / \$ 36.00$

Copyright (C) 2012 by The American Association for Thoracic Surgery doi:10.1016/j.jtcvs.2012.05.026
}

cases, the $\mathrm{LN}$ dissection is performed after the lung resection has been completed. Although visualization can be difficult, proper use of a 30-degree thoracoscope will facilitate the dissection. On the right, the dissection is begun at levels 2 and 4 by incising the mediastinal pleura just posterior to the superior vena cava and then grasping the nodal tissue with a forceps. The nodal packet is then dissected laterally from the superior vena cava and trachea, over the ascending aorta, to the level of the subclavian artery. Judicious use of electrocautery is necessary to avoid injury to the right vagus nerve, or more superiorly, the right recurrent laryngeal nerve. Some surgeons prefer a harmonic scalpel or liberal use of hemostatic clips to avoid hemorrhage from lymphatic or bronchial vessels during the dissection. The azygous vein may be sacrificed if necessary to adequately expose the lowlevel 4 nodes.

On the left, with the lung retracted inferiorly, levels 5 and 6 are accessed by incising the pleura overlying the aortic arch, posterior to the phrenic nerve. The left vagus also should be identified and preserved. The dissection is then continued into the aortopulmonary window along the left main bronchus to remove station $4 \mathrm{~L}$. This must be done carefully to avoid injury to the left recurrent laryngeal nerve.

Identification of the level $7 \mathrm{LN}$ station begins with retracting the lung medially and dividing the posterior mediastinal pleura. On the right, the medial border of the bronchus intermedius may be followed; on the left, the mainstem bronchus provides the lateral border. The nodal packet is dissected free from the underlying posterior pericardium, moving superiorly from the inferior pulmonary vein until the carina is visualized. Level 8 and 9 LNs are easily identified and excised when mobilizing the inferior pulmonary ligament and retracting the lung superiorly.

N1 nodes should be dissected during the course of individual hilar bronchovascular dissection. These nodes, levels 10 to 13 , should be individually labeled and sent for pathologic analysis. In addition, a dialogue between surgeon and pathologist about the importance of examining LNs within the lobectomy specimen itself should be made explicit.

\section{EFFICACY}

Several studies have examined the ability of mediastinal lymphadenectomy by VATS to effectively dissect and sample N2 level LNs (Table 1). Kondo and colleagues ${ }^{12}$ performed the first of these observing 6 patients who first underwent lobectomy by VATS for a stage I NSCLC of the right lung with a mediastinal node dissection, followed by thoracotomy and examination for residual LNs. An 
TABLE 1. Mediastinal lymph node dissection via video-assisted thoracoscopic surgery versus thoracotomy

\begin{tabular}{|c|c|c|c|}
\hline \multicolumn{4}{|c|}{ No. of lymph nodes removed } \\
\hline Author & VATS & Thoracotomy & $\begin{array}{c}P \\
\text { value }\end{array}$ \\
\hline Kondo and colleagues ${ }^{12}$ & $38 *$ & - & \\
\hline Sugi and colleagues ${ }^{13}$ & Hilar: 8.2 & Hilar: 8.4 & .88 \\
\hline & Mediastinal: 13.0 & Mediastinal: 13.4 & \\
\hline Sagawa and colleagues ${ }^{14}$ & $39 \dagger$ & - & \\
\hline $\begin{array}{l}\text { Watanabe and } \\
\text { colleagues }^{15}\end{array}$ & 32.0 & 29.4 & NS \\
\hline Scott and colleagues ${ }^{16}$ & 15 & 19 & .147 \\
\hline $\begin{array}{l}\text { Denlinger and } \\
\text { colleagues }^{17}\end{array}$ & 7.1 & 8.9 & .006 \\
\hline
\end{tabular}

No. of lymph node stations sampled

$\begin{array}{llll}\text { D'Amico and colleagues }^{18} & 4 & 4 & .06\end{array}$

All values are mean or median as described within each study. VATS, Video-assisted thoracoscopic surgery; $N S$, not significant. *There were 1.3 remaining LNs at the time of subsequent thoracotomy. $\dagger$ There were 1.2 remaining LNs at the time of subsequent thoracotomy

average of 38 LNs per patient were removed via VATS with additional remaining LNs found in only 2 of the 6 patients. The overall percentage of nodes remaining at the time of thoracotomy was only $3.4 \%$. A similar study by Sagawa and colleagues ${ }^{14}$ examined 29 patients over a 3 -year period who underwent lobectomy by VATS. An average of 40.3 LNs were dissected via VATS on the right side, with only 1.2 remnant nodes. On the left side, an average of 37.1 nodes were resected, again with 1.2 remnant nodes, once again confirming that near-complete $\mathrm{LN}$ dissection was feasible via thoracoscopy.

Sugi and colleagues ${ }^{13}$ conducted a prospective study in which 100 patients were randomized to open thoracotomy or lobectomy by VATS. No differences in tumor characteristics between the 2 groups were identified. At the conclusion of the study, no difference was noted in the number of LNs dissected between the open and VATS groups. A nonrandomized study from 2005 compared the number of LNs dissected at the time of lobectomy by VATS $(\mathrm{n}=191)$ with the number of LNs at the time of thoracotomy $(\mathrm{n}=159)$ and again found no difference. ${ }^{15}$ Of note, a significantly higher percentage of patients in the VATS group had adenocarcinoma when compared with the thoracotomy group.

Three additional studies examining this issue have been published within the past 2 years. ${ }^{16-18}$ A secondary analysis of the American College of Surgeons Oncology Group Z0030 trial compared patients who underwent lobectomy by VATS with patients who underwent thoracotomy. ${ }^{16}$ A total of 752 of the original participants of the study were included within the secondary analysis, of whom 66 underwent thoracoscopic lobectomy and 686 underwent an open procedure. The original trial compared patients who underwent complete mediastinal LN dissection with those who underwent systematic sampling. Only those patients undergoing complete dissection were included in this secondary analysis. No significant difference was found in the median number of total LNs retrieved between the 2 groups. In addition, patients who underwent lobectomy by VATS had fewer chest tubes draining for more than 7 days $(1.5 \%$ vs $10.8 \%, P=.029)$ and a shorter length of stay ( 5 vs 7 days, $P<.001$ ).

A retrospective review by Denlinger and colleagues ${ }^{17}$ compared 79 patients who underwent lobectomy by VATS with 464 patients who underwent open lobectomy for stage I NSCLC. Their study found a small, although significant, difference in the number of LNs dissected between each group (Table 1). Survival between the 2 groups was similar, although the majority of patients were followed for only 1 year postoperatively. No difference was noted in the number of N1 nodes resected. Patients undergoing left-sided resection had significantly fewer level 7 nodes resected via thoracoscopy ( 0.4 vs $1.0, P<.001)$, as well as level 5 and 6 nodes ( 0.5 vs $1.1, P<.04)$. Most recently, D'Amico and colleagues ${ }^{18}$ examined the National Comprehensive Cancer Network's NSCLC Outcomes Database. This study compared the number of nodal stations sampled during thoracoscopic lobectomy $(n=199)$ with the numbered sample during open lobectomy $(n=189)$ and found no difference (4 stations on average in each group).

Perhaps more important than the absolute number of LNs resected or stations sampled in the determination of effectiveness of lymphadenectomy by VATS, however, is reporting of overall and disease-free survival in lobectomy by VATS series. Suboptimal thoracoscopic LN dissection might be expected to result in understaging of patients with NSCLC and be reflected as decreased survival of patients with early-stage disease. Several large studies have not shown this to be the case, with both survival and recurrence rates being similar in patients treated with VATS or open lobectomy for stage I disease. ${ }^{9,10}$

\section{CONCLUSIONS}

VATS mediastinal LN dissection is equivalent to a comparable dissection via a thoracotomy in the hands of an experienced thoracoscopic surgeon with regard to both morbidity and oncologic efficacy. We recommend that all patients undergoing a lobectomy by VATS undergo a complete mediastinal LN evaluation by sampling or complete dissection at the time of surgical resection.

\section{References}

1. Goldstraw P, Crowley J, Chansky K, Giroux DJ, Groome PA, Rami-Porta R, et al. The IASLC Lung Cancer Staging Project: proposals for the revision of the TNM stage groupings in the forthcoming (seventh) edition of the TNM Classification of malignant tumours. J Thorac Oncol. 2007;2:706-14.

2. Darling GE, Allen MS, Decker PA, Ballman K, Malthaner RA, Inculet RI, et al. Randomized trial of mediastinal lymph node sampling versus complete 
lymphadenectomy during pulmonary resection in the patient with $\mathrm{N} 0$ or N1 (less than hilar) non-small cell carcinoma: results of the American College of Surgery Oncology Group Z0030 trial. J Thorac Cardiovasc Surg. 2011;141: 662-70.

3. Ettinger DS, Akerley W, Bepler G, Blum MG, Chang A, Cheney RT, et al. Nonsmall cell lung cancer. J Natl Compr Canc Netw. 2010;8:740-801.

4. Lardinois D, De Leyn P, Van Schil P, Porta RR, Waller D, Passlick B, et al. ESTS guidelines for intraoperative lymph node staging in non-small cell lung cancer. Eur J Cardiothorac Surg. 2006;30:787-92.

5. Scott WJ, Howington J, Feigenberg S, Movsas B, Pisters K, American College of Chest Physicians. Treatment of non-small cell lung cancer Stage I and Stage II: ACCP evidence-based clinical practice guidelines (2nd edition). Chest. 2007; 132(3 Suppl):234S-42S.

6. Gajra A, Newman N, Gamble GP, Kohman LJ, Graziano SL. Effect of number of lymph nodes sampled on outcome in patients with stage I non-small cell lung cancer. J Clin Oncol. 2003;21:1029-34.

7. Little AG, Rusch VW, Bonner JA, Gaspar LE, Green MR, Webb WR, et al. Patterns of surgical care of lung cancer patients. Ann Thorac Surg. 2005;80:2051-6.

8. Paul S, Altorki NK, Sheng S, Lee PC, Harpole DH, Onaitis MW, et al. Thoracoscopic lobectomy is associated with lower morbidity than open lobectomy: a propensity-matched analysis from the STS database. J Thorac Cardiovasc Surg. 2010;139:366-78.

9. Yan TD, Black D, Bannon PG, McCaughan BC. Systematic review and metaanalysis of randomized and nonrandomized trials on safety and efficacy of video-assisted thoracic surgery lobectomy for early-stage non-small-cell lung cancer. J Clin Oncol. 2009;27:2553-62.

10. Flores RM, Ihekweazu UN, Rizk N, Dycoco J, Bains MS, Downey RJ, et al. Patterns of recurrence and incidence of second primary tumors after lobectomy by means of video-assisted thoracoscopic surgery (VATS) versus thoracotomy for lung cancer. J Thorac Cardiovasc Surg. 2011;141:59-64.

11. McKenna RJ. Vats lobectomy with mediastinal lymph node sampling or dissection. Chest Surg Clin N Am. 1995;5:223-32.

12. Kondo T, Sagawa M, Tanita T, Sato M, Ono S, Matsumura Y, et al. Is complete systematic nodal dissection by thoracoscopic surgery possible? A prospective trial of video-assisted lobectomy for cancer of the right lung. J Thorac Cardiovasc Surg. 1998;116:651-2.

13. Sugi K, Kaneda Y, Esato K. Video-assisted thoracoscopic lobectomy achieves a satisfactory long-term prognosis in patients with clinical stage Ia lung cancer. World J Surg. 2000;24:27-31.

14. Sagawa M, Sato M, Sakurada A, Matsumura Y, Endo C, Handa M, et al. A prospective trial of systematic nodal dissection for lung cancer by video-assisted thoracic surgery: can it be perfect? Ann Thorac Surg. 2002;73:900-4.

15. Watanabe A, Koyanagi T, Ohsawa H, Mawatari T, Nakashima S, Takahashi N, et al. Systematic node dissection by VATS is not inferior to that through an open thoracotomy: a comparative clinicopathologic response study. Surgery. 2005;138:510-7.

16. Scott WJ, Allen MS, Darling G, Meyers B, Decker PA, Putnam JB, et al. Videoassisted thoracic surgery versus open lobectomy for lung cancer: a secondary analysis of data from the American College of Surgeons Oncology Group Z0030 randomized clinical trial. J Thorac Cardiovasc Surg. 2010;139:976-83.

17. Denlinger CE, Fernandez F, Meyers BF, Pratt W, Zoole JB, Patterson GA, et al. Lymph node evaluation in video-assisted thoracoscopic lobectomy versus lobectomy by thoracotomy. Ann Thorac Surg. 2010;89:1730-6.

18. D'Amico TA, Niland J, Mamet R, Zornosa C, Dexter EU, Onaitis MW. Efficacy of mediastinal lymph node dissection during lobectomy for lung cancer by thoracoscopy and thoracotomy. Ann Thorac Surg. 2011;92:226-32. 